\title{
Rooteomics: The Challenge of Discovering Plant Defense-Related Proteins in Roots
}

\author{
Angela Mehta ${ }^{1, *}$, Beatriz S. Magalhães ${ }^{1, a}$, Djair S. L. Souza ${ }^{1, a}$, Erico A. R. Vasconcelos ${ }^{1, a}$, \\ Luciano P. Silva ${ }^{1, a}$, Maria Fátima Grossi-de-Sa ${ }^{1,2, a}$, Octávio L. Franco ${ }^{2,3, a}$, Paulo H. A. da Costa ${ }^{1, a}$, \\ and Thales L. Rocha, ${ }^{1, a}$
}

${ }^{1}$ Embrapa Recursos Genéticos e Biotecnologia, Brasília, Brazil; ${ }^{2}$ Centro de Análises Proteômicas e Bioquímicas, Pro-
grama de Pós-Graduação em Ciências Genômicas e Biotecnologia, Universidade Católica de Brasília, Brasília, Brazil;
${ }^{3}$ Departamento de Biologia, Universidade Federal de Juiz de Fora, Juiz de Fora, Brazil

\begin{abstract}
In recent years, a strong emphasis has been given in deciphering the function of genes unraveled by the completion of several genome sequencing projects. In plants, functional genomics has been massively used in order to search for gene products of agronomic relevance. As far as root-pathogen interactions are concerned, several genes are recognized to provide tolerance/resistance against potential invaders. However, very few proteins have been identified by using current proteomic approaches. One of the major drawbacks for the successful analysis of root proteomes is the inherent characteristics of this tissue, which include low volume content and high concentration of interfering substances such as pigments and phenolic compounds. The proteome analysis of plant-pathogen interactions provides important information about the global proteins expressed in roots in response to biotic stresses. Moreover, several pathogenic proteins superimpose the plant proteome and can be identified and used as targets for the control of viruses, bacteria, fungi and nematode pathogens. The present review focuses on advances in different proteomic strategies dedicated to the challenging analysis of plant defense proteins expressed during bacteria-, fungi- and nematode-root interactions. Recent developments, limitations of the current techniques, and technological perspectives for root proteomics aiming at the identification of resistance-related proteins are discussed.
\end{abstract}

Keywords: Roots, proteome, 2DE, mass spectrometry.

\section{INTRODUCTION}

Root tissues represent an important structure for plant growth and development, and are continuously invaded by microorganisms, which cause deleterious effects that culminate in the development of disease and/or death of the plant. Roots are intrinsically complex tissues to explore and slow progress has been made in discovering plant-genes and proteins in these tissues governing the interaction of plant pathogens and their hosts. Most studies are focused on the developmental aspects of roots and with the increase in the availability of expressed sequence tag (EST) sequences, several genes involved in cell cycle, cell growth, abiotic stresses and hormone signaling have been identified [1-5].

In recent years, the application of proteomic approaches as a tool for global expression analysis and protein identification has been highly efficient in the field of protein research. Improvements in the main techniques and equipments for 2-DE (bidimensional gel electrophoresis) and mass spectrometry have allowed a high throughput analysis of protein expression in different fields. While the proteomics research is greatly advanced in animals, plant proteomics has

\footnotetext{
*Address correspondence to this author at the Embrapa Recursos Genéticos e Biotecnologia, PqEB Av. W/5 Norte Final, Asa Norte, CEP 70770-900 Brasília, DF, Brazil; Tel: +55 61 3448-4901; Fax: +55 61 3340-3658;

E-mail: amehta@cenargen.embrapa.br

${ }^{a}$ These authors are arranged alphabetically by author's first names since they contributed equally to the work.
}

not yet reached a sufficient level of complexity to identify and study plant proteins involved during the pathogen-host plant interactions. Many proteins involved in the mechanisms of response to biotic/abiotic stress signals are present in low abundance and thus are not easily detectable in crude extracts. Major studies in plant proteomics involve subcellular proteomes, including chloroplasts, mitochondria, nuclei and plasma membranes [6-11] and most of them still rely on 2-DE separations of crude cellular extracts.

The study of proteins has also become progressively more important since it is now well established that there is little correspondence between the transcript and protein levels $[12,13]$. Post-translational modifications such as the removal of signal peptides, phosphorylation, glycosylation, ubiquitination, among others are important processes for protein function and subcellular localization which are not accounted for using genomic strategies [14]. Therefore, proteomics is playing an increasingly important role in addressing these issues and has become a necessary and complementary approach in the post-genomic era. Furthermore, by analyzing the proteins being expressed during a specific condition, information regarding the genes/proteins that are co-regulated and act together in response to a given stress can be identified. Nevertheless, the root proteomics (here termed rooteomics) analysis is still insipient when compared to other plant tissues and even more when compared to other organisms such as prokaryotes, yeasts and mammalians [15]. One of the major factors responsible for the limited data re- 
garding root proteomics is related to low protein and tissue amounts. Interestingly, Mooney et al. [16] showed that proteins involved in disease resistance represented $13 \%$ of root proteins compared to $7 \%$ identified in leaves. Theses results indicate that root tissue is an excellent target to study plantpathogen interactions and the use of differential proteomic studies can aid in the discovery of resistance- and defenserelated proteins.

\section{PROTEIN ANALYSIS TOOLS FOR ROOTEOMICS}

\section{Sample Preparation}

In general, protein sample preparation is a key step in any proteomic approach. When considering the extraction of proteins in plant tissue, the difficulty often resides in their low overall intrinsic amounts, the presence of proteases and contaminants such as polyphenols, polysaccharides, lipids and secondary metabolites that usually hinder an efficient protein extraction [17]. In addition, the proteomic profile is often dominated by the more abundant components, which considerably limit the number of proteins that can be successfully identified. For these reasons, most protocols for protein extraction from plant tissues include a protein precipitation step, in order to concentrate the total protein content in the sample and clean it from contaminants. In this sense, a common approach for protein extraction has been to homogenize the plant material in the presence of liquid nitrogen, precipitate the protein content in a trichloroacetic acid/acetone solution and re-solubilize the pellet in a chaotropic agent [18]. Due to its simplicity, it remains the preferred protocol of total protein extraction from root tissue, as demonstrated by recent proteomic studies of wheat [19], maize [20], Medicago trunculata [21], rice [22] and ginseng [23] roots.

An alternative procedure has been to extract proteins with phenol and subsequently precipitate them in ammonium acetate and methanol [24]. Although fewer research groups adopt this protocol, the procedure was recently judged more efficient in terms of the number of proteins detected in tomato root tissue, when compared to the number extracted with the standard trichloroacetic acid/acetone method [25]. Despite this result, the type of protocol employed is in fact greatly dependent upon the type of tissue and the subsequent purification strategies. In some instances, the application of both protocols to the same tissue sample can result in different proteomic profiles, as was demonstrated in banana, apple and potato leaves [26].

Another method recently proposed by Dumas-Gaudot et al. [27] optimizes the amount of root material under study. These authors report a method for the extraction of RNA and proteins from the same sample. Ground material is homogenized in buffered phenol and RNA is further collected from the aqueous phase, while proteins are recovered from the phenolic phase [27]. This is an interesting alternative when genomic and proteomic approaches are intended.

The need to enrich samples with specific proteins has also contributed to the optimization of extraction protocols aiming the study of plant subproteomes. In this sense, from the perspective of identifying symbiosis-related proteins, the possibility of restricting the tissue of interest to the actual nodule and peribacteriod membranes has proved successful. The protocols employed to study the nodule proteome are quite diverse, but they have generally recurred to differential centrifugation steps. Recently, this type of procedure has been demonstrated in proteomic studies of $M$. trunculata root nodules infected by Agrobacterium tumefaciens [28], in soybean root nodules infected by Bradyrhizobium japonicum [29], in pea root and Woogenellup roots infected by Rhizobium leguminosarum [30, 31], in Lotus japonicus root nodules infected by Mesorhizobium loti [32]. Furthermore, the characterization of membrane-associated proteins has also been possible with an additional chloroform/methanol extraction step, as demonstrated in the comparative proteomic study of $M$. truncatula roots inoculated with the fungus Glomus intraradices [33].

When considering root-pathogen interactions and the subsequent identification of resistance-related and pathogenesis-related (PR) proteins, no particular effort has been made towards the physical separation of the pathogen from the root tissue before proteomic analysis. In fact, much of the literature on the subject simply assesses the differences observed between proteomic profiles of infected versus noninfected roots, as in the case of $M$. truncatula infected by the fungi Aphanomyces euteiches [34]. One avenue left to explore remains the possibility of studying the pathogen and the root individual proteomes upon interaction. The specific structures formed within the root tissue upon infection, such as specialized giant cells in the case of nematode infection [35], or localized infected cell populations could well be the target of specific proteomic studies. To this end, the application of laser capture microdissection could prove a powerful new tool towards the isolation of these structures and advance the understanding of the proteomic profiles of the initial stages of root infection. Although much of the work describing the application of this technique in the characterization of plant-microbe interaction has focused on gene expression [36], it could well be extended in the field of root proteomics.

\section{Two Dimensional Gel Electrophoresis}

In recent years, the field of proteomics has expanded considerably and several new technologies have been developed and applied to an enormous variety of biological questions [37]. Although some authors have suggested that bidimensional gel electrophoresis (2-DE) is an ancient and surpassed technique, this procedure has been frequently utilized in plant proteomic studies. In fact, promising alternative technologies such as multidimensional protein separation, protein arrays and others have emerged recently. However, 2-DE is currently the only technique that can be routinely applied for quantitative expression profiling of large sets of complex protein mixtures such a root cell lysates [38]. Although 2-DE technology is not properly cheap, the equipments are much more accessible than mass spectrometers, for example. This particularity makes proteomic studies possible for several research groups located in developing countries, spreading the proteomic science around the world. It is true that protein identification is an important step in proteomic analysis and mass spectrometry-based strategies has contributed enormously in this aspect. Thus, the recent enthusiasm in proteomic studies is a result of the union of 
techniques based on 2-DE and those focused on mass spectrometry, and this union has been responsible for the increase in the functional assignment of proteins and genes in various organisms, including plants. The 2-DE technology began to be explored in the 1970s [39] and several modifications have been added to this classical technique, especially for plant tissues analyses [40]. Immobilized $\mathrm{pH}$ gradients and gels, as well as power supplies and gel supports are now commercially available and have clearly improved reproducibility and decreased wasted time. By using these benefits, several good quality 2-D gels have been obtained, generating valuable information for the understanding of root metabolism and physiology.

Initially, model plants such as Arabidopsis thaliana and $M$. truncatula were used to develop extraction and gel protocols. Therefore, 2-DE associated to peptide mass fingerprinting was used to investigate the natural variation in the root proteome among eight $A$. thaliana ecotypes [41]. Comparison of 2-D maps demonstrated that only one-quarter of spots were shared by all accessions, suggesting that rooteomics could be a valuable tool to understand natural variations of plants and also to compare susceptible and resistant varieties to isolate resistance proteins.

The proteome knowledge achieved in root models was applied to crop plants, aiming to solve agricultural problems and find biotechnological targets and/or tools. However, most studies have focused on developmental aspects. Liu et al. [20] produced 2-D gels of primary maize roots, aiming to identify proteins that are differentially accumulated during root growth. Differential spots were identified by MS showing that two proteins that were shown to accumulate differentially between wild-type and mutant roots can be linked to lignin metabolism, giving clues on genes that might be involved in the developmental switch that results in the initiation of lateral roots [20]. By using high-resolution 2-DE, the cassava (Manihot esculenta Crantz) root proteome was also evaluated [42]. Gel image analyses revealed an average of 1467 electrophoretically resolved spots on fibres and 1595 spots on tuber in the $\mathrm{pH} \mathrm{3-10} \mathrm{range.} \mathrm{As} \mathrm{cassava} \mathrm{is} \mathrm{a} \mathrm{major}$ source of energy in the diet of more than 700 million people, particularly in the developing countries of South America, Africa and Asia, the proteomic approach could be useful for a better understanding of protein and carbohydrate accumulation in tuber. Therefore, results reported by Sheffield et al. [42] not only facilitate insights into the molecular processes underlying root physiology and differentiation, but can also give valuable information for cassava genetic improvement programs in order to solve some problems as disease susceptibility, low production and reduced nutritional quality.

New improvements in electrophoresis tools such as the development of algorithms for gel image analysis [43], difference gel electrophoresis (DIGE) that facilitates complex protein comparison analysis by labelling different samples with fluorescents dyes [44] and dilute Immobiline ${ }^{\mathrm{TM}}$ gels for the resolution of large proteins [45] are already being used in biomedical research. The utilization of these techniques in plant research could contribute for the development of plant proteomics, specifically for proteomic processes involving root pathogen interaction.
Although by no means perfect, 2-DE coupled with mass spectrometry remains the core technology for separating and identifying complex protein mixtures in proteomic projects at least for the foreseeable future [38]. Rooteomic studies aiming at the identification of agronomically important proteins is a field that can be largely explored using both these techniques. It is certain an array of novel interesting proteins will be discovered using these approaches.

\section{Gel-Free Systems}

Despite the undeniable applicability of 2-DE in the field of proteomic research, the limitations of the technique in terms of its unsuitability to identify less abundant proteins [46] or to characterize membrane proteins, together with the difficulties to automate the procedure, have prompted the search for gel-free systems in order to improve the extent of protein separation [47]. One way to circumvent these limitations has been through the incorporation of multidimensional chromatographic steps before mass spectrometric analysis [48]. This procedure incorporates ion-exchange and reversephase capillary columns directly linked to a nanospray mass spectrometer. The samples applied to these columns consist of digested proteins with several proteolytic enzymes which greatly increases the number of peptide targets available for the identification of the parent protein. In order to ensure the feasibility of this method, a good genome database (e.g. cDNA library) should be available for the organism in question, which is why this approach has only been successful so far in the field of plant proteomics when characterizing the rice proteome [49].

On a much smaller scale, the application of liquid chromatography for protein separation instead of 2-DE has proved successful in a proteomic approach aiming to characterize the small protein content of $M$. truncatula root tips [50]. In this case, the protein extraction protocol was simplified and consisted of a single extraction step with $30 \%$ acetonitrile and $0.1 \%$ trifluoroacetic acid followed by size exclusion and reverse phase chromatographic purification steps. Despite this attempt, the lack of literature available on the application of gel-free systems to the study of rootmicrobe interactions reinforces the practicality of the 2-DE methods for protein separation, but at the same time opens up new possibilities for large scale protein identification projects through the optimization of multidimensional chromatographic steps prior to mass spectrometric analysis.

\section{Mass Spectrometry Identification Methods}

Mass spectrometry (MS) has become an essential tool for protein identification. Recent developments and technical improvements have allowed a large scale analysis of proteins, which have accompanied the increasing amount of proteins being analyzed by the 2-DE techniques. Accurate molecular mass information provided by MS and tandem MS experiments has enabled a rapid comparison of differentially expressed proteins in plants in diverse biological conditions.

Mass spectrometry is a powerful tool for protein identification and also enables the characterization of posttranslational modifications (PTMs) as well as the identification of protein-protein interactions and multisubunit com- 
plexes [14]. Proteins can be initially resolved by electrophoretic (top-down) or chromatographic (bottom-up) approaches. Further enzymatic digestion allows the identification of these proteins via peptide mass fingerprinting (PMF) using MS or via de novo sequencing using tandem MS $\left(\mathrm{MS} / \mathrm{MS}\right.$ and $\mathrm{MS}^{\mathrm{n}}$ ).

Peptides generated by enzymatic digestion have taken advantage of two major MS ionization methods: matrixassisted laser desorption/ionization (MALDI) and electrospray ionization (ESI). In MALDI, peptides are cocrystallized with a large molar excess of a small molecular organic acid on a metallic plate following the desorption and ionization by intense and short pulses from a laser beam. In ESI, peptides in an acidic solution are sprayed in a fine mist and the solution in the droplets evaporates leaving the peptide ionized.

Besides the development of the MALDI and ESI ionization methodologies, improvement in MS devoted to proteomic studies has also resulted from advances in mass analyzers. The time-of-flight (TOF), quadrupole (Q), ion trap (IT) and Fourier transform ion cyclotron (FTIC) are the major types of mass analyzers currently interfacing MALDI and ESI. Each of them shows specific features and several instruments use two or more mass analyzers to separate the ions according to their mass-to-charge ration. Finally, a detector is used to register the number of ions emerging from the analyzer.

Root proteomic analyses of plant-microorganism interactions described to date were mainly focused on differential protein composition induced by symbiotic microbes [51-53, $27,54,32,29]$. In contrast, the study of proteins differentially expressed in response to root pathogens is a neglected area of proteomics. Only few investigations were carried out on altered protein composition induced by root pathogens $[34,55,56]$. Most of these studies have used a 2-DE approach followed by in-gel trypsin digestion and MALDITOF MS and several proteins have been identified.

MALDI-TOF MS is a highly advantageous strategy when compared to $\mathrm{NH}_{2}$ terminal sequencing, which was the only method available for protein identification until recently. However, some problems need to be taken into consideration, such as protein amounts. As mentioned in this review, roots have intrinsically low amounts of proteins and therefore, the chances of a successful identification by MS or MS/MS is low. In our experience, when analyzing the rooteomics of cotton and coffee, a successful identification was obtained for only $30 \%$ of the proteins analyzed. Therefore, care must be taken to optimize the amount of proteins obtained from the root tissue in order to successfully identify proteins by using the MALDI-TOF MS approach.

\section{ROOT-PATHOGEN INTERACTIONS}

Nutrient acquisition is an essential process for the survival of all heterotrophic organisms. As primary nutrient source, plants represent an important carbon source for a wide number of organisms. Several species of microorganisms live in close association with plants colonizing the surface (epiphytic colonization) or tissues (endophytic colonization), and sometimes causing diseases (pathogenic coloniza- tion). The events that trigger the establishment of these interactions are activated by the recognition of specific signal molecules associated to plants and microorganisms, which are detected by sensorial proteins. Upon detection of these stimuli, there is a continuous process of response between plants and microorganisms that characterizes the plantmicroorganism interaction. Several plant factors such as pathogen recognition receptors and phenolic compounds as well as pathogen proteins and molecules including virulence factors and exopolysaccharides play important roles in plantmicroorganism relation and are determinants in the nature of the interaction [57].

Extensive genomic studies have revealed several resistance and defense-related genes expressed during pathogen infection. After the recognition of the pathogen by the plant, signal transduction pathways are triggered, which result in the production of reactive oxygen species, accumulation of pathogenesis-related proteins and phytoalexins, as well as localized cell death [58, 59]. Among the defense-related genes reported are chitinases, $\beta$-1,3-glucanases, chalcone synthases and peroxidases. Regarding proteomic analyses, some efforts have been made aiming at the comprehension of root-fungi, -bacteria and -nematode interactions, and the findings are discussed below. Some of the root proteins differentially expressed during plant-microorganism interaction identified by proteomic approaches are listed in Table $\mathbf{1}$.

\section{Proteomics of Root-Fungi Interactions}

Regarding the proteomic analysis of root-pathogen association, the most studied interaction is that of root-fungi. Several reports have shown the use of proteomics for the isolation of proteins of agronomic relevance including chitinases, pathogenesis-related proteins, among others. However, still little proteomic information is available regarding the biochemical and physiological interactions in this host-parasite system. Moreover, the molecular bases of the interaction between pathogenic fungi and roots are not well understood.

The proteomic tools offer an excellent way to evaluate the host proteome during the host-parasite interaction process. Compared to the number of publications on the proteomics of symbiotic interactions (nitrogen-fixing and arbuscular mycorrhizal), the use of this strategy appears rather limited in the area of plant responses to pathogens. The amount of root material available for analysis is frequently a major drawback for more detailed studies. Similar difficulties have been reported in the symbiotic root-fungi interactions in M. truncatula [27]. These authors report that few studies have been performed in the appresoria stage, in which limited amounts of root are available; making proteomic studies a difficult task. The extraction of proteins and RNAs from the same sample is one of the alternatives to overcome this problem. Techniques that allow this analysis have been developed for root-fungi interaction and have been used successfully [27]. This strategy could be applied for other plant-microbial interactions in order to optimize the results obtained.

Additionally, plants are able to synthesize and secrete enzymes that are able to degrade the cell wall of the invading pathogen and these enzymes are often classified as patho- 
Table 1. Root Proteins Differentially Expressed During Plant-Microorganism Interactions Identified by Proteomic Studies

\begin{tabular}{|c|c|c|c|}
\hline Disease resistance response protein pi 49 & M. truncatula & A. euteiches & Colditz et al., 2004 \\
\hline $\begin{array}{l}\text { Pathogenesis-related protein class } 10 \\
\text { (PR10) }\end{array}$ & M. truncatula & A. euteiches & Colditz et al., 2004 \\
\hline Glutathione-S-transferase & M. truncatula & Glomus mosseae & Bestel-Corre et al., 2002 \\
\hline Cytochrome-c-oxidase & M. truncatula & Glomus mosseae & Bestel-Corre et al., 2002 \\
\hline Fucosidase & M. truncatula & Glomus mosseae & Bestel-Corre et al., 2002 \\
\hline Pathogenesis-related protein Prb1 & Oryza sativa & Azoarcus sp. & Miché et al., 2006 \\
\hline Chaperonin 21 precursor & clover cultivar Woogenellup & Rhizobium leguminosarum bv. trifolii & Morris and Djordjevic, 2001 \\
\hline L-ascorbate peroxidase & M. truncatula & $\mathrm{N}$-acyl homoserine lacton (AHL)-treated & Mathesius et al., 2003 \\
\hline $\begin{array}{l}\text { Hipersensitive-induced response protein } \\
\qquad \text { (HIR1) }\end{array}$ & M. truncatula & $\mathrm{N}$-acyl homoserine lacton (AHL)-treated & Mathesius et al 2003 \\
\hline Superoxide dismutase & M. truncatula & $\mathrm{N}$-acyl homoserine lacton (AHL)-treated & Mathesius et al 2003 \\
\hline PR10-1 protein & M. truncatula & $N$-acyl homoserine lacton (AHL)-treated & Mathesius et al 2003 \\
\hline Peroxidase & M. truncatula & $\mathrm{N}$-acyl homoserine lacton (AHL)-treated & Mathesius et al 2003 \\
\hline Aconitate hydratase & M. truncatula & Sinorhizobium meliloti & Van Noorden et al., 2007 \\
\hline Chitinase & C. canephora & M. paranaensis & - \\
\hline Pathogenesis-related protein class 10 & C. canephora & M. paranaensis & - \\
\hline Quinone reductase 2 & G. hirsutum & M. incognita & - \\
\hline 14KDa polypeptide & G. hirsutum & M. incognita & Callahan et al. 1997 \\
\hline
\end{tabular}

genesis-related proteins because high-level expression is normally induced upon infection. By using 2-DE, the root protein profiles of $M$. truncatula after Aphanomyces euteiches pathogen infection were analyzed [55]. Several differentially expressed proteins in response to the infection were identified by MALDI-TOF-MS and the majority of the induced proteins belonged to the family of the class 10 of PR proteins. Other protein spots were also identified as putative cell wall proteins and enzymes of the phenylpropanoidisoflavonoid pathway, including an isoliquiritigenin (chalcone) 2-O-methyltransferase (cOMT) and a chalcone reductase (CHR), which are required for the production of medicarpin, the major phytoalexin accumulated in response to fungal pathogens. More recently, a comparison of M. trunculata lines with different susceptibility to the A. euteiches was performed and two proteasome alpha subunits in the more resistant line were identified [34].

The number of proteins spots identified in the $M$. truncatula root-fungus interactions (500 proteins) is impressively low, when compared to the number of transcripts sequenced using a genomic approach (5000 transcripts). This result represents another challenge for proteomic analysis and can be explained by the limitations of the proteomic tools and methods such as protein extraction protocols that do not allow the isolation of proteins with certain biophysical properties, such as hydrophobicity (hydrophobic proteins are lost due to low solubility), limitations in the $\mathrm{p} I$ range for 2-DE separation and low abundance proteins that can not be observed in the 2-DE gels. One of the techniques that can over- 
come this problem is the MudPIT (multidimensional protein identification technology), already successfully applied to plant systems [60]. However, quantification of expression levels is not possible with this technique. These aspects need to be taken into consideration when analyzing the protein expression in a given condition.

Another strategy that can be applied for plant disease control is the analysis of the pathogen proteins, which can be identified and used as targets. Pathogenic fungi have several effector proteins that play a key role in parasitic colonization of plants [61]. Apoplastic effectors are secreted into the plant extracellular space, where they interact with extracellular targets and surface receptors. By using a proteomic approach, Apoga et al. [62] investigated the role of the extracellular matrix secreted by the cereal pathogenic fungus Bipolaris sorokiniana. However, the proteins isolated from 2-DE gels and analyzed by MS revealed no significant matches to sequences available in public databases. Protein identification by using the MS technology is highly dependent on the public databases, and the amount of information constantly deposited is impressively large. However, attention must be drawn to the fact that a large number of proteins with unknown functions or not yet isolated can be completely ignored when protein homology is searched. This is also true for root proteins. An interesting result was obtained by Fizames et al. [63], who analyzed root transcriptomics of Arabidopsis plants using the SAGE (Serial Analysis of Gene Expression) technique. These authors reported 6000 different transcript tags, which showed no match to the Arabidopsis genes and suggest that a significant amount of transcripts present in roots originate from unknown or wrongly annotated genes. This is an intriguing result and may reflect the difficulty in root protein identification.

Several proteomic studies on symbiotic fungus-root interactions have also been conducted and these organisms, although beneficial to the plant, seem to induce an array of defense-related proteins during colonization. Proteome analysis has identified proteins involved in mycorrhiza development and functioning including proteins involved in defense response and root physiology [64]. An interesting case is that of Trichoderma, which is a fungus that can increase root growth, control deleterious non-pathogenic root microflora, destroy toxic metabolites produced by deleterious microflora and control root pathogens [65]. Several studies have shown that root colonization by Trichoderma strains results in increased levels of defense-related plant enzymes, including various peroxidases, chitinases, $\beta$-1,3-glucanases, and the lipoxygenase-pathway. Trichoderma species have been reported as potentially useful for biological control, since they are able to attack or inhibit the growth of plant pathogens directly. Proteomic studies of the interaction of Trichoderma and maize seedlings grown from treated and non treated seeds were investigated by 2 -DE. About $40 \%$ of the proteins observed in the presence of Trichoderma were not detected in untreated plants [65]. Similarly, Marra [66] identified 29 proteins related to the triple interaction among bean roots (Phaseolus vulgaris) with the fungi Botrytis cinerea and Rhizoctonia solani and its antagonist Trichoderma. Proteins with differential expression patterns were evaluated by MS and in root proteome, PR proteins and other factors related to resistance were associated to the interaction be- tween the plant and the two pathogenic fungi as well as with the antagonist. These results are in agreements with the findings of Harman et al. [65], which showed that Trichoderma has the property of inducing resistance to many pathogenic microorganisms.

Another important approach is the analysis of the Trichoderma proteome in response to the interaction with the plant. The proteins identified in this interaction process may shed some light over the processes that trigger plant defense, and may be used for the induction of resistance in plants. Some efforts have been made in this direction. Suárez et al. [67] analyzed the extracellular proteome secreted by Trichoderma harzianum in the presence of different fungal cell walls. A combination of liquid chromatography and mass spectrometry allowed the identification of a novel aspartic protease, which showed $44 \%$ identity with the aspartic proteinase polyporopepsin (EC 3.4.23.29) from the basidiomycete Irpex lacteus. In summary, the results discussed here exemplify the range of proteomic applications that can successfully be applied to the study of fungi-root molecular interactions.

\section{Root-Bacteria Interactions}

Plant-bacteria interactions have been extensively studied over the years and various plant genes involved in the response to bacterial phytopathogen infection have been identified [58,68-70]. However, few studies have focused on root-bacteria association, and these studies have mainly employed genomic techniques. Ditt et al. [71 recently reported the transcriptomic analysis of Arabidopsis plants in response to A. tumefaciens infection and several up-regulated genes encoding known defense proteins were identified.

Regarding the proteomic approach, Mathesius et al. [56] reported the analysis of $M$. truncatula roots in response to Pseudomonas aeruginosa quorum-sensing signals. The recognition of these signals by the plant is important for the response to the invading pathogens. Several proteins involved in defense, including PR proteins, peroxidases, superoxide dismutase and a hypersensitive induced response protein (HIR1) were identified [56]. The lack of information in this field shows that there is insipient knowledge regarding protein expression in roots in response to bacterial infection. This is an interesting area of investigation and should be better explored.

The root-symbiosis association has been the most studied root-bacteria interaction and as in symbiotic fungi-root interaction, defense-related genes have been reported in nodulated roots. A pioneering proteomic work aiming to study this type of interaction was performed with the legume Melilotus alba infected by the bacterium Sinorhizobium meliloti [72]. This study revealed over 250 proteins induced or up-regulated upon infection, which were mainly of bacterial origin present in the nodules as compared with the roots. Other studies followed, such as that reported by Morris and Djordjevic [73] and more recently by Miché et al. [74] and van Noorde et al [75], in which proteins involved in rootbacteria interaction were identified. These data reinforce the importance of the study of roots for the discovery of resistance-related genes and proteins in plants. 
Bacteria belonging to the Rhizobium genus may also establish beneficial or harmful relationships with plants. The pathogenic strains of this legume endosymbiont contain vir genes, which cause the formation of tumors or hairy roots [76]. Strains of $R$. rhizogenes were shown to be able to induce hairy roots or tumors in plants and also to nodulate $P$. vulgaris under natural environmental conditions [76]. In $M$. truncatula, a time-course analysis of root protein profiles was investigated using 2-DE and MS identification after inoculation with the nitrogen fixing bacterium Sinorhizobium meliloti. An M. truncatula leghemoglobin induced in nodulated roots was identified, as well as an elongation factor $\mathrm{Tu}$ from $S$. meliloti, while another one could not be assigned a function. These results emphasize the usefulness of proteome analysis in identifying molecular events occurring in plant root symbioses and also call attention to the fact that microorganism proteins are not separated from the root tissues when the interaction is being analyzed. This is especially important when a function can not be assigned to the proteins and therefore it is not possible to determine if the protein was expressed in the plant or in the microorganism.

\section{Root-Nematode Interactions}

The current knowledge on plant-nematode interactions has reached the frontline regarding new scientific approaches. A high amount of information has been generated based on genome and transcriptome analysis, however few studies have focused on the proteomic profiles of plants infected by nematodes. When the nematodes invade plant roots and establish as the sedentary form, several plant genes are up- or down-regulated in order to form the nematode feeding sites [77]. Diverse resistance genes have been identified as induced in infected roots, all conferring resistance against these pathogens [78]. Activated defense genes include peroxidase, chitinase, lipoxygenase, extensin, and proteinase inhibitors [77]. The discovery of these genes expressed upon nematode parasitism can provide important information about natural resistance in plants. Studies have shown the efficiency of the bioactive anti-nematodes molecules such as orizocistatin and esporamin (proteinase inhibitors) that confer resistance to $M$. incognita and Heterodera schachtii, respectively $[79,80]$. Several other genes have been isolated and presented a potential application for nematode control in transgenic plants. Some proteins encoded by these genes include the $\gamma$-aminobutyric acid (GABA) [81] and lectins [82]. The products of the nematode resistance (Nem-R) genes can be specifically active against some nematode species or pathotypes [78] and include the genes Gro1-4 [83], Mi-1 [84], Hs1pro-1 [85], Hero A [86-88], Cre1 [89], among others. Secondary metabolites such as phytoalexins are also synthesized in the roots and confer higher resistance levels to nematode pathogens $[90,91]$. All these genes however, were isolated using genomic approaches. A proteomic strategy could be applied in order to complement these data and isolate the proteins encoded by these genes.

The lack of data regarding proteomic studies focused on root-nematode interaction is intriguing. Jaubert and colleagues [92] shed some light on this point when 2-DE and microsequencing were employed to analyze the proteome of the pathogen Meloidogyne incognita stilet. A total of 7 proteins were identified, including a calreticulin that is believed to be related with infectivity of nematodes in plants [92]. Regarding root-nematode proteomics, a study performed by Callahan et al. [93] reported one- and two-dimensional polyacrylamide gel electrophoresis (PAGE) of resistant and susceptible cotton (Gossypium hirsutum L.) root protein extracts. Several polypeptides were differentially expressed in response to the root-knot nematode infection. A polypeptide with $14 \mathrm{kDa}$ was abundantly and differentially expressed in young galls of the resistant isoline 81-249 at 8 days after inoculation. The amino acid sequences obtained did not reveal considerable homologies with other sequences. However, this novel root knot nematode-inducible $14 \mathrm{kDa}$ protein can be related with a specific resistance in nematode galls [93].

Besides the identification of natural anti-nematode molecules, the profile of genes or proteins induced by the nematodes during the feeding site formation can generate potential targets for reverse-genetics. An example of this response is the case of an expansin gene expressed during Meloidogyne javanica parasitism that acts as a facilitator of cell expansion in vivo, being extremely important for the expansion of the giant cell. The LeEXPA5-antisense transgenic roots reduce the nematode ability to complete its life cycle [94]. Therefore, proteomic approaches can act together with other functional genomic tools for identification of specific protein / RNA targets and for the development of new transgenic crops resistant to nematodes.

Our research group has been studying proteins differentially expressed in cotton and coffee resistant cultivars infected with M. incognita and Meloidogyne paranaensis, respectively. We have used a proteomic approach to analyze the proteins expressed in these plant genotypes and compared infected versus non-infected roots by 2 -DE. Several differentially expressed proteins could be observed in the gels [95] and some proteins were identified by MS/MS. One differentially expressed protein in infected coffee roots was identified as a chitinase class III of $C$. arabica (Table 2), known to be involved in defense responses to pathogens [96]. Also a constitutive protein expressed in infected and non-infected coffee roots was identified as a PR protein of Vitis quinquangularis (Table 2). It is known that most resistance genes are constitutively expressed in plants [78] and this may be the case of the PR protein identified in coffee. In cotton, we have identified a protein similar to Triticum monococcum quinone reductase $2(\mathrm{QR} 2)$ (Table 2). In plants these proteins catalyze the divalent reduction of quinones to hydroquinones protecting the plant cells from oxidative damages [97]. Our results emphasize the importance of root proteomics in the isolation of resistance and defense- related proteins and genes.

\section{PERSPECTIVES}

As emphasized in this review, there is insipient data on rooteomics analysis focused on root-pathogen interactions. Analysis of 2-DE based approaches provides a convenient way to study and identify proteins that are regulated in response to stress conditions. Moreover, the potential of these techniques in the identification of defense/resistance-related proteins is undeniable. Future discovery of novel proteins involved in pathogen response could lead to the isolation of 
Table 2. Identification of $C$. canpehora and G. hirsutum Proteins by Peptide Sequencing

\begin{tabular}{|c|c|c|c|c|c|c|}
\hline Spot $\mathbf{n}^{\circ}$ & Peptide Sequence & Protein Identification & Accession \# & Mr (gel) & $\begin{array}{l}\text { pI } \\
\text { (gel) }\end{array}$ & Identity \\
\hline Coffee 1 & LSLGGAPNLSS & chitinase & gi|4633666 & 28 & 5.8 & $100 \%$ \\
\hline Coffee 2 & YEVTSSIPPAR & $\begin{array}{l}\text { Pathogenesis-related } \\
\text { protein }\end{array}$ & gi|89887947 & 17 & 7.2 & $88 \%$ \\
\hline Cotton 1 & TDAPIITLVELTEADGVLFGFPTR & quinone reductase 2 & gi|58500257 & 35 & 7.0 & $82 \%$ \\
\hline
\end{tabular}

genes, which could be introduced into agronomically important crops aiming to obtain resistant plants.

Rooteomics analyses present several challenges, which include the presence of low amounts of proteins in root tissues and limitations of protein extraction protocols currently available. Another important task when studying rooteomics is the absence of similarity hits when peptide sequences are searched in the current databases. When analyzing structural and functional genome sequencing projects, around $30 \%$ of the genes sequenced represent hypothetical proteins or are no hits. In the case of mass spectrometry analysis of root proteins with no genome sequence available, the identification of these proteins can be a major problem. In this review, we have emphasized the promising analysis of rooteomics research in order to identify proteins and genes of agronomic relevance to be used in the development of a sustained agriculture in the future. The proteome analyses have been increasingly performed and the current techniques promises a great deal for better understanding the root-pathogen interactions

\section{REFERENCES}

[1] Scheres, B., Benfey, P. and Dolan L. (2002) In The Arabidpsis book (Somerville, C.R. and Meyerowitz, E.M. Eds) Rockville, MD: American Society of Plant Biologists (http://www.aspb.org/ download/arabidopsis/scheres.pdf).

[2] Kohler, A., Delaruelle, C., Martin, D., Encelot, N. and Martin, F. (2003) FEBS Lett., 542, 37-41.

[3] Jiang, Y. and Deyholos, M.K. (2006) BMC Plant Biol., 6, 25.

[4] Kwasniewski, M. and Szarejko, I. (2006) Plant Physiol., 141, 1149-58.

[5] Mouchel, C.F., Osmont, K.S. and Hardtke, C.S. (2006) Nature, 443, 458-461.

[6] Peltier, J. B., Friso, G., Kalume, D. E., Roepstorff, P., Nilsson, F.,Adamska, I. and van Wijk, K. J. (2000) Plant Cell, 12, 319-342.

[7] Ferro, M., Salvi, D., Brugiere, S., Miras, S., Kowalski, S., Louwagie, M., Garin, J., Joyard, J. and Rolland, N. (2003) Mol. Cell Proteomics, 2, 325-345.

[8] Werhahn, W. and Braun, H.P. (2002) Electrophoresis, 23, 640-646.

[9] Bae, M. S., Cho, E. J., Choi, E.-Y. and Park, O. K. (2003) Plant J., 36, 652-663.

[10] Kawamura, Y. and Uemura, M. (2003) Plant J. 36, 141-154.

[11] Gonzalez-Camacho, F. and Medina, F.J. (2007) Methods Mol. Biol., 355, 63-72.

[12] Gygi, S.P., Rochon, Y., Franza, B.R. and Aebersold, R. (1999) Mol. Cell Biol., 19, 1720-30.

[13] Chen, G., Gharib, T.G., Huang, C.C., Taylor, J.M., Misek, D.E., Kardia, S.L., Giordano, T.J., Iannettoni, M.D., Orringer, M.B., Hanash, S.M. and Beer, D.G. (2002) Mol. Cell. Proteomics, 1, 304313.

[14] Jensen, O.N. (2006) Nature Mol. Cell Biol., 7, 391-403.

[15] Agrawal, G.K. and Rakwal, R. (2006) Mass Spectrom. Rev., 25, 153
[16] Mooney, B.P., Miernyk, J.A., Greenlief, C.M. and Thelen, J.J. (2006) Physiologia Plantarum, 128, 237-250.

[17] Tsugita, A. and Kamo, M. (1999) Methods Mol. Biol., 112, 95-97.

[18] Damerval, C., de Vienne, D., Zivy, M. and Thiellement, H. (1986) Electrophoresis, 7, 52-54.

[19] Bahrman, N., Gouy, A., Devienne-Barret, F., Hirel, B., Vedele, F. and Le Gouis, J. (2005) Plant Sci., 168, 81-87.

[20] Liu, Y., Lamkemeyer, T., Jakob, A., Mi, G., Zhang, F, Nordheim, A. and Hochholdinger, F. (2006) Proteomics, 6, 4300-4308.

[21] Mathesius, U., Keijzers, G., Natera, S.H.A., Weinman, J.J., Djordjevic, M.A. and Rolfe, B.G. (2001) Proteomics, 1, 1424-1440.

[22] Konishi, H., Kitano, H. and Komatsu, S. (2005) Plant Cell Environ., 28, 328-339.

[23] Kim, S., Kim, J.Y., Kim, E.A., Kwon, K.H., Kim, K.W., Cho, K., Lee, J.H., Nam, M.H., Yang, D.C., Yoo, J.S. and Park, Y.M. (2003) Proteomics, 3, 2379-2392.

[24] Hurkman, W.J. and Tanaka, C.K. (1986) Plant Physiol., 81, 802806.

[25] Saravanan, R.S. and Rose, J.K.C. (2004) Proteomics, 4, 2522-2532.

[26] Carpentier, S.C., Witters, E., Laukens, K., Deckers, P., Swennen, R. and Panis, B. (2005) Proteomics, 5, 2497-2507.

[27] Dumas-Galdot, E., Aminour, N., Weidmann, S., Bestel-Corre, G., Lenogue, S., Gianinazzi-Pearson, V. and Gianinazzi, S. (2004) Proteomics, 4, 451-453.

[28] Valot, B., Gianinazzi, S. and Eliane, D.G. (2004) Phytochem., 65, 1721-1732.

[29] Panter, S., Thomson, R., de Bruxelles, G., Laver, D., Trevaskis, B. and Udvardi, M. (2000) Mol. Plant Microbe Interact., 13, 325-333.

[30] Saalbach, G., Erik, P. and Wienkoop, S. (2002) Proteomics, 2, $325-$ 337.

[31] Morris, A.C. and Djordjevic, M.A. (2001) Electrophoresis, 22, 586-598

[32] Wienkoop, S. and Saalbach, G. (2003) Plant Physiol., 131, 10801090.

[33] Valot, B., Dieu, M., Recorbet, G., Raes, M., Gianinazzi, S. and Dumas-Gaudot, E. (2005) Plant Mol. Biol., 59, 565-580.

[34] Colditz, F., Braun, H.P., Jacquet, C., Niehaus, K. and Krajinski, F. (2005) Plant Mol. Biol., 59, 387-406

[35] Davis, E.L., Hussey, R.S., Baum, T.J., Bakker, J. and Schots, A. (2000) Ann. Rev. Phytopathol., 38, 365-396.

[36] Ramsay, K., Jones, M.G.K. and Wang, Z.H. (2006) Mol. Plant Pathol., 7, 429-435.

[37] Wilkins, M.R., Appel, R.D., Van Eyk, J.E., Chung, M.C., Gorg, A., Hecker, M., Huber, L.A., Langen, H., Link, A.J., Paik, Y.K., Patterson, S.D., Pennington, S.R., Rabilloud, T., Simpson, J., Weiss, W. and Dunn, M.J. (2006) Proteomics, 6, 4-8

[38] Gorg, A., Weiss, W. and Dunn, M.J. (2004) Proteomics, 4, $3665-$ 3685 .

[39] O'Farrel, P.H. (1975) J. Biol. Chem., 250, 4007-4021

[40] Weiss, W. and Gorg, A. (2007) Methods Mol. Biol., 355, 121-143.

[41] Chevalier, F., Martin, O., Rofidal, V., Devauchelle, A.D., Barteau, S., Sommerer, N. and Rossignol, M. (2004) Proteomics, 4, 13721381.

[42] Sheffield, J., Taylor, N., Fauquet, C. and Chen, S. (2006) Proteomics, 6, 1588-1598.

[43] Blueggel, M., Chamrad, D. and Meyer, H.E. (2004) Curr. Pharm. Biotechnol., 5, 79-88.

[44] Ornstein, D.K. and Petricoin, E.F. (2004) Oncology New York, 18, 521-529. 
[45] Bruschi, M., Seppi, C., Arena, S., Musante, L., Santucci, L., Balduini, C., Scaloni, A., Lanciotti, M., Righetti, P.G. and Candiano, G. (2005) J. Prot. Res., 4, 1304-1309.

[46] Gygi, S.P., Corthals, G.L., Zhang, Y., Rochon, Y. and Aebersold, R. (2000) Proc. Natl. Acad. Sci. USA, 97, 9390-9395.

[47] Rabilloud, T. (2002) Proteomics, 2, 3-10.

[48] Link, A.J., Eng, J., Schieltz, D.M., Carmack, E., Mize, G.J., Morris, D.R., Garvik, B. M. and Yates, J.R. (1999) Nat. Biotechnol., 17, 676-682.

[49] Koller, A., Washburn, M. P., Lange, B. M., Andon, N. L., Deciu, C., Haynes, P. A., Hays, L., Schieltz, D., Ulaszek, R., Wei, J., Wolters, D. and Yates, J. R. (2002) Proc. Natl. Acad. Sci. USA, 99, 11969-11974

[50] Zhang, K.R., McKinlay, C., Hocart, C.H. and Djordjevic, M.A. (2006) J. Prot. Res., 5, 3355-3367.

[51] Jorrín, J.V., Rubiales, D., Dumas-Gaudot, E., Recorbet, G., Maldonado, A., Castillejo, M. A. and Curto, M. (2006) Euphytica, 147, 37-47.

[52] Cánovas, F. M., Dumas-Gaudot, E., Recorbet, G., Jorrin, J., Mock, H-P. and Rossignol, M. (2004) Proteomics, 4, 285-298.

[53] Catalano, C. M., Lane, W. S. and Sherrier, D. J. (2004) Electrophoresis, 25, 519-531.

[54] Djordjevic, M. A. (2004) Sinorhizobium meliloti metabolism in the root nodule: a proteomic perspective. Proteomics 4, 1859-1872.

[55] Colditz, F., Nyamsuren, O., Niehaus, K., Eubel, H., Braun, H. -P. and Krajinski, F. (2004) Plant Mol. Biol., 55, 109-120.

[56] Mathesius, U., Mulders, S., Gao, M. S., Teplitski, M., CaetanoAnolles, G., Rolfe, B. G. and Bauer, W.D. (2003) Proc. Natl. Acad. Sci. USA, 100, 1444-1449.

[57] Brencic, A. and Winans, S.C. (2005) Microbiol. Mol. Biol. Rev., 69, 155-194.

[58] McDowell, J.M. and Dangl, J.L. (2000) Trends Biochem. Sci., 25, 79-82.

[59] da Cunha, L., McFall, A.J. and Mackey, D. (2006) Microbes Infect., 8, 1372-81

[60] Maor, R., Jones, A., Nuhse, T.S., Studholme, D.J., Peck, S.C. and Shirasu, K. (2007) MudPIT analysis of ubiquitinated proteins in plants. Mol. Cell Proteomics, http://www.mcponline.org/cgi/reprint/M600408-MCP200v1

[61] Kamoun, S. (2005) Ann. Rev. Phytopathol., 44, 41-60

[62] Apoga, D., Ek, B. and Tunlid, A. (2001) FEMS Microbiol. Lett., 197, 145-150.

[63] Fizames C, Muños S, Cazettes C, Nacry P, Boucherez J, Gaymard F, Piquemal D, Delorme V, Commes T, Doumas P, Cooke R, Marti J, Sentenac H and Gojon A. (2004) Plant Physiol., 134, 67-80.

[64] Bestel-Corre, G., Dumas-Gaudot, E., Poinsot, V., Dieu, M., Dierick, J.F., Tuinen, D.V., Remacle, J., Gianinazzi-Pearson, V. and Gianinazzi, S. (2002) Electrophoresis, 23, 122-137

[65] Harman, G.E., Howell, C.R., Viterbo, A., Chet, I. and Lorito, M., (2004) Nat. Rev. Microbiol., 2, 43-56.

[66] Marra, R., Ambrosino, P., Carbone, V., Vinale, F., Woo, S.L., Ruocco, M., Ciliento, R., Lanzuise, S., Ferraioli, S., Soriente, I., Gigante, S., Turra. D., Fogliano, V., Scala, F. and Lorito, M. (2006) Curr. Genet., 50, 307-321.

[67] Suárez, M.B., Sanz, L., Chamorro, M.I., Rey, M., González, F.J., Llobell, A. and Monte, E. (2005) Fungal Gen. Biol., 42, 924-934

[68] Dangl, J.L. and Jones, J.D. (2001) Nature, 411, 826-833.

[69] Shao, F., Golstein, C., Ade, J., Stoutemyer, M., Dixon, J.E. and Innes, R.W. (2003) Science, 301, 1230-1367

[70] He, P., Chintamanani, S., Chen, Z., Zhu, L., Kunkel, B.N., Alfano, J.R., Tang, X. and Zhou, J.M. (2004) Plant J., 37, 589-602.
[71] Ditt, R.F., Kerr, K.F., de Figueiredo, P., Delrow, J., Comai, L. and Nester, E.W. (2006) Mol. Plant Microbe Interact., 19, 665-81.

[72] Natera, S.H.A., Guerreiro, N. and Djordjevic, M.A. (2000) Mol. Plant Microbe Interact., 13, 995-1009

[73] Morris, A.C. and Djordjevic, M.A. (2001) Electrophoresis., 22, 586-98

[74] Miché, L., Battistoni, F., Gemmer, S., Belghazi, M. and ReinholdHurek, B. (2006) Mol. Plant Microbe Interact., 19, 502-11.

[75] van Noorden, G.E., Kerim, T., Goffard, N., Wiblin, R., Pellerone, F.I., Rolfe, B.G. and Mathesius, U. (2007) Plant Physiol., 144 1115-31.

[76] Velazquez, E., Peix, A., Zurdo-Pineiro, J.L., Palomo, J.L., Mateos, P.F., Rivas, R., Munoz-Adelantado, E., Toro, N., GarciaBenavides, P. and Martinez-Molina, E. (2005) Mol. Plant Microbe Interact., 18, 1325-32.

[77] Gheysen, G. and Fenoll, C. (2002) Annu. Rev. Phytopathol., 40, 191-219.

[78] Williamson, V.M. and Kumar, A., (2006) Trends Gen., 22, 396-403

[79] Urwin, P.E., Lilley, C.J., McPherson, M.J. and Atkinson, H.J. (1997) Plant J., 12, 455-461.

[80] Cai, D., Thurau, T., Tian, Y., Lange, T., Yeh, K.W. and Jung, C. (2003) Plant Mol. Biol., 51, 839-849.

[81] McLean, M.D., Yevtushenko, D.P., Deschene, A., Cauweberghe, O.R.V., Makhmoudova, A., Potter, J.W., Bown, A.W. and Barry, J. (2003) Mol. Breeding, 11, 277-285.

[82] Ripoll, C., Favery, B., Lecomte, P., Van Damme, E., Peumans, W., Abad, P. and Jouanin, L. (2003) Plant Sci., 164, 517-523.

[83] Paal, J., Henselewski, H., Muth, J., Meksem, K., Menendez, C.M., Salamini, F., Ballvora, A. and Gebhardt, C. (2004) Plant J., 38, 285-297.

[84] Seah, S., Yaghoobi, J., Rossi, M., Gleason, C.A. and Williamson, V.M. (2004) Theor. Appl. Genet., 108, 1635-1642.

[85] Thurau, T., Kifle, S., Jung, C. and Cai, D. (2003) Plant Mol. Biol. 52, 643-660.

[86] Poch, H.L.C.A, López, R.H.M. and Kanyuka, K. (2006) Plant Cell Environ., 29, 1372-1378.

[87] Sobczak, M., Avrova, A., Jupowicz, J., Phillips, M.S., Ernst, K. and Kumar, A. (2005) Mol. Plant Microbe Interact., 18, 158-168

[88] Ernst, K., Kuma, A., Kriseleit, D., Kloos, Dorothee-U., Philips, M. and Ganal, M.W. (2002) Plant J., 31(2), 127-136.

[89] De Majnik, J., Ogbonnaya, F.C., Moulet, O. and Lagudah, E.S. (2003) Mol. Plant Microbe Interact., 16, 1129-1134

[90] Hanawa, F., Yamada, T. and Nakashima, T. (2001) Phytochemistry, 57, 223-228.

[91] Baldridge, G.D., O`Neill, N.R. and Samac, D.A. (1998) Plant Mol. Biol., 38, 999-1010.

[92] Jaubert, S., Ledger, T.N., Laffaire, J.B., Piotte, C., Abad, P. and Rosso, M.N. (2002) Mol. Biochem. Parasitol., 121, 205-211.

[93] Callahan, F.E., Jenkins, J.N., Creech, R.G. and Lawrence, G.W (1997) J. Cotton Sci., 1, 38-47.

[94] Gal, T.Z., Aussenberg, E.R., Burdman, S., Kapulnic, Y. and Koltai, H. (2006) Planta, 224, 155-162.

[95] Franco, O.L., Andrade, A.E., Pereira, J.L., Costa, P.H.A., Rocha, T.L., Barros, E.V.S.A. Grossi-de-Sá, M.F., Carneiro, R.M.D.G. Carneiro, R.G. and Mehta, A. J. Phytopathol., (submitted)

[96] Li, H.Y., Yang, G.D., Shu, H.R., Yang, Y.T., Ye, B.X., Nishida, I and Zheng C.C. (2006) Plant Cell Physiol., 47, 154-63.

[97] Sparla, F., Tedeschi, G., Pupillo, P. and Trost, P. (1999) FEBS Lett., 463, 382-386 